\title{
Digging the pupfish out of its hole: Risk analyses to guide harvest of Devils Hole pupfish for captive breeding
}

The Devils Hole pupfish is restricted to one wild population in a single aquifer-fed thermal pool in the Desert National Wildlife Refuge Complex. Since 1995 the pupfish has been in a nearly steady decline, where it was perched on the brink of extinction at $35-68$ fish in 2013 . A major strategy for conserving the pupfish has been the establishment of additional captive or "refuge" populations, but all ended in failure. In 2013 a new captive propagation facility designed specifically to breed pupfish was opened. I examine how a captive population can be initiated by removing fish from the wild without unduly accelerating extinction risk for the pupfish in Devils Hole. I construct a count-based PVA model, parameterized from estimates of the intrinsic rate of increase and its variance using counts in spring and fall from 19952013, to produce the first risk assessment for the pupfish. Median time to extinction was 26 and 27 years from spring and fall counts, respectively, and the probability of extinction in 20 years was $26-33 \%$. Removing individuals in the fall had less risk to the wild population than harvest in spring. For both spring and fall harvest, risk increased rapidly when levels exceeded six adult pupfish per year for three years. Extinction risk was unaffected by the apportionment of total harvest among years. A demographic model was used to examine how removal of different stage classes affects the dynamics of the wild population based on reproductive value (RV) and elasticity. Removing eggs had the least impact on the pupfish in Devils Hole; RV of an adult was roughly 25 times that of an egg. To evaluate when it might be prudent to remove all pupfish from Devils Hole for captive breeding, I used the count-based model to examine how extinction risk related to pupfish population size. Risk accelerated when initial populations were less than 30 individuals. Results are discussed in relation to the challenges facing pupfish recovery compared to management of other highly endangered 
2 Digging the Pupfish Out of its Hole: Risk Analyses to Guide Harvest of Devils Hole Pupfish

Steven R. Beissinger, Department of Environmental Science, Policy \& Management,

6 Phone: 510-499-5516

7 Email: beis@berkeley.edu 


\section{INTRODUCTION}

9 The Devils Hole pupfish (Cyprinodon diabolis) may have the smallest geographic range of any

10 vertebrate in the wild. This species is restricted to a single population and occurs primarily in the

11 upper 10 meters of Devils Hole, an aquifer-fed thermal pool $\left(\sim 33.5^{\circ} \mathrm{C}\right)$ and limestone cavern with

12 a surface area of $50 \mathrm{~m}^{2}$ that is located $17 \mathrm{~m}$ below the land surface in the Desert National Wildlife

13 Refuge Complex in Nye County, Nevada (Andersen \& Deacon 2001; Baugh \& Deacon 1983a).

14 Pupfish spawning takes place predominately on a shallow $(\sim 0.35 \mathrm{~m})$, submerged $\sim 2 \mathrm{x} 4 \mathrm{~m}$ shelf

15 (Hausner et al. 2013; James 1969). It is the only fish in Devils Hole, where it has resided since

16 climate warming caused regional drying beginning 20,000 years ago (Szabo et al. 1994).

The Devils Hole pupfish (DHP) has played an important role in the history of the conservation movement. In 1952 Carl Hubbs, a pioneer of western ichthyology, convinced

19 President Harry Truman to designate Devils Hole as a disjunct part of Death Valley National

Monument to protect both its unique geological features and the pupfish (Riggs \& Deacon 2004).

21 The DHP was among the initial species listed when the U.S. Endangered Species Preservation

22 Act was passed in 1967. A monitoring program was begun that used scuba divers to count fish

23 and initial counts found 100-250 individuals in the early 1970's (Riggs \& Deacon 2004). Soon

24 after, the DHP was the subject of a historic four-year legal battle over water rights that

25 culminated in the U.S. Supreme Court (1976 Cappert v. United States). The decision caused a

26 cessation of groundwater mining from further dewatering the aquifer for development in the

27 Amargosa Valley and nearby Ash Meadows (Riggs \& Deacon 2004), and the case had a major

28 influence on ground water rights in the region.

29 With the cessation of groundwater pumping, water levels rose in Devils Hole as did DHP

30 numbers (Andersen \& Deacon 2001), which reached a maximum count of 541-548 individuals in

31 1980, 1990 and 1995 (Figure 1). Since 1995, however, the pupfish in Devils Hole has been in a

32 nearly steady decline, where it was perched on the brink of extinction at 35-68 fish in 2013. 
33 Hypothesized causes of decline include food limitation due to changes in the Devils Hole algal

34 and invertebrate communities (K.P. Wilson, pers. comm., 3 June 2014), mutational meltdown

35 caused by centuries of reduced genetic variation (Martin et al. 2012), and climate warming

36 resulting in increased water temperatures and decreased dissolved oxygen (Hausner et al. 2013;

37 Hillyard et al. 2014). The population decline was amplified by the accidental deaths of at least 72

38 pupfish in Sept. 2004 in larval traps that were washed into Devils Hole during a flash flood

39 (Manning \& Wullschleger 2004).

40 A major strategy for conserving the DHP, in addition to securing Devils Hole, has been

41 the establishment of captive or "refuge" populations (Baugh \& Deacon 1988; Wilcox \& Martin

42 2006). However, past attempts have not been successful. Between 1969 and 2012, multiple

43 attempts were made to propagate the DHP in captivity and establish refuges. Typically these

44 efforts removed 12-30 pupfish at a time from Devils Hole. They were transported to 14 different

45 locations ranging from managed efforts in established, commercial aquaria to constructed and

46 natural ponds or springs with less oversight. All ended in failure, with some populations lasting

47 for 1-2 decades and others for 1-2 years (Karam 2005; U.S.N.P.S. 2012; Wilcox \& Martin 2006).

48 Reasons for failure, when known, were varied and included equipment or water supply failure,

49 predation by native and exotic species, vandalism, failure to reproduce, and hybridization.

Now in response to the recent population collapse and imminent threat of extinction, a

51 new captive propagation facility has been built and, unlike previous efforts, was designed

52 specifically to breed pupfish. It was built in nearby Ash Meadows, and received a total of 60

53 DHP eggs from August 2013 to January 2014. The Ash Meadows facility provides a new

54 opportunity for successful captive breeding, but it also presents a challenge. Without an obvious

55 track record of captive breeding success, can a captive population be initiated without unduly

56 accelerating the risk of extinction of the DHP in Devils Hole? Which life stages of the fish

57 should be collected to minimize impact on the wild population? On the other hand, if the 
58 trajectory of decline for the DHP continues, will there be a moment when all individuals should

59 be removed from the wild in order to maximize the genetic diversity for captive breeding to

60 succeed? This occurred for the California condor (Gymnogyps californianus) in 1986 when

61 evidence indicated little hope of survival in the wild (Snyder \& Snyder 1989). That controversial

62 and difficult decision was implemented after much debate within the U.S. Fish and Wildife

63 Service over whether to proceed with removing the last wild condors, and after litigation by its

64 conservation partner, the National Audubon Society, to prevent it. Removing the last wild

65 individuals turned out to be the right decision, as it secured a gene pool for the subsequently

66 highly successful captive propagation program (Snyder \& Snyder 2000), although reintroduction

67 to the wild remains problematic (Walters et al. 2010). Successful captive breeding was foreseen

68 for condors based on captive propagation undertaken with surrogate species, such as the Andean

69 condor (Vultur gryphus), and similar possibilities exist for the pupfish based on experiences with

70 the DHP and its congenerics (e.g., Baugh \& Deacon 1983b; Deacon et al. 1995; Lema \& Nevitt

$71 \underline{2006})$.

72 Here I produce the first risk assessment for the Devils Hole Pupfish. I construct a count-

73 based population viability model to project the risk of extinction for the DHP parameterized from

74 recent biannual pupfish surveys. I then use the model to evaluate how the number of individuals

75 removed for captive breeding and the timing of harvest affects population viability of the DHP in

76 Devils Hole. Next I build a matrix population model to ask what the impact of removing pupfish

77 eggs, early life stage (larval) individuals, or adults will be on DHP population dynamics based on

78 patchy demographic data, expert opinion and data borrowing from closely-related species.

79 Finally, I return to the count-based population model to ask how extinction risk relates to DHP

80 population size to evaluate when it might be prudent to remove the remaining pupfish from

81 Devils Hole for captive breeding. In these applications of population models to project extinction

82 risk, commonly called population viability analysis or PVA (Beissinger \& McCullough 2002), I 
83 evaluate conservation decisions by comparing differences in projected outcomes among

84 management options incorporated into the models rather than basing recommendations solely on 85 the projected rates of extinction (Lotts et al. 2004; McCarthy et al. 2003; Ralls et al. 2002; $\underline{\text { Reed }}$

86 et al. 2002).

\section{MATERIALS AND METHODS}

\section{Modeling Risk and Harvest Strategies for Captive Breeding Using DHP Counts}

89 Visual counts of pupfish from 1972 to 2013, made by SCUBA divers in the pool and by observers

90 on the shallow shelf, were obtained from Death Valley National Park personnel (Figure 1). See

91 Dzul et al. (2012) for survey details and sources of error. Counts of pupfish did not distinguish

92 between adults and detectable early life stage individuals, and were conducted on about a

93 monthly basis from 1972-1983. By 1985 counts were mainly done biannually, in the spring

94 (March-April) during the main breeding season of the pupfish and in the fall (Sept.-Oct.) during a

95 second but reduced pulse of breeding. Only one count per season was conducted in most years,

96 which precluded the use of $N$-mixture models of population estimation that require repeated

97 sampling (Royle \& Dorazio 2008). In the absence of survey-level covariates of effort, I was

98 unable to use a single visit conditional likelihood approach to estimate abundance (Lele et al.

99 2012; Solymos et al. 2012). Thus, I choose to use the maximum count for each season in each

100 year as an estimate of the population size, creating two time series of counts. Treating counts

101 separately provided independently derived estimates of population trends and permitted seasonal

102 evaluation of harvest options.

103 I calculated the rate of population growth $\left(r=\ln \left(N_{t^{+1}} / N_{t}\right)\right.$ from pairs of counts of

104 population size $(N)$ from consecutive years $(t)$. I then fit one density-independent and two

105 density-dependent models of population growth to the period when pupfish numbers grew (1972-

106 1995) and the period of population decline (1996-2013) following Morris and Doak (2002): 
$\ln \left(N_{t+1} / N_{t}\right)=r+\varepsilon_{i}(1)$ Exponential (density-independent):

$\ln \left(N_{t+1} / N_{t}\right)=r\left[1-\left(\frac{N_{t}}{K}\right)+\varepsilon_{i}\right]$

108 (2) Logistic (density-dependent):

$$
\ln \left(N_{t+1} / N_{t}\right)=r\left[1-\left(\frac{N_{t}}{K}\right)^{\theta}+\varepsilon_{i}\right]
$$

109 (3) Theta-logistic (density-dependent):

110 where $r$ growth rate, $K=$ carrying capacity, $\theta$ adjusts how population growth changes with $N$,

111 and $\varepsilon_{i}=$ is the variance or deviation in the natural logarithm of population growth $(\ln r)$ centered

112 around zero. Akaike's Information Criterion (AIC) corrected for small sample size (AICc) was

113 used to quantify model fit (Burnham \& Anderson 2002).

114 To model extinction risk in the wild, the pupfish population in Devils Hole was projected

115 forward in time for 100 years with separate models for spring and fall using each season's

116 estimates fitted values for average population growth rate, carrying capacity (when appropriate),

117 and annual deviations from mean growth rates $\left(\varepsilon_{i}\right)$ estimated from 1996-2013 to yield the median

118 time (years) to extinction and probability of extinction. Starting population size was set to the

119 number of pupfish counted in 2013 for spring (35) and fall (68), and 10,000 iterations were run.

120 Fractional numbers of individuals were rounded down each year.

121 Using $\varepsilon_{i}$ to model annual variation among counts has contrasting effects on the resulting

122 estimate of extinction risk. The $\varepsilon_{i}$ term incorporates implicit effects captured in DHP count

123 fluctuations including: (1) demographic, environmental, and genetic stochasticity; (2)

124 catastrophes; and (3) sampling variation. Nevertheless, these processes were not explicitly

125 modelled. The inclusion of sampling variation in the estimate of $\varepsilon_{i}$ will overestimate variation in

126 population growth and inflate extinction risk. However, in the absence of explicit incorporation 
127 in the model of genetic processes (e.g., inbreeding depression), extinction risk may be

128 underestimated. As I am unable to determine the magnitude of each effect, estimates of

129 extinction risk are best interpreted when compared among different scenarios.

130 To evaluate the effects of different strategies for removing individuals to initiate a captive

131 breeding program on the wild population, I used the models that best described DHP population

132 dynamics for spring and fall from 1996-2013, and harvested (removed) different numbers of

133 individuals (0-14) at the start of each simulated year. Harvest was done for each of three years to

134 mimic building a new population for captive propagation. Median time to extinction and

135 probability of extinction were evaluated from 10,000 iterations.

136 I used the same model to examine how risk of extinction changes with DHP population

137 size to evaluate when to remove all pupfish individuals from Devils Hole based solely on changes

138 in wild population risk without considering genetic goals for the captive population. The

139 stochastic count-based PVA model was run for 10,000 iterations parameterized with the 1996-

1402013 measures of population growth, incrementally changing the initial population size.

\section{Deterministic Matrix Demographic Model to Evaluate Age Classes to Remove}

142 A deterministic demographic model was developed to evaluate the effects of removing

143 individuals of different life stages on DHP population dynamics by calculating for each life stage

144 its reproductive value (i.e., expected future number of offspring produced) and elasticity

145 (sensitivity of population growth to changes in demographic parameters associated with each

146 stage). I sought opinions for constructing and parameterizing the model from $15 \mathrm{DHP}$ and

147 fisheries experts that attended the DHP Risk Analysis Workshop (8 Nov. 2013). Demographic

148 data available for the DHP are so limited, and the uncertainties so large, that I could not justify

149 the choice of particular rates or scenarios. Instead, I generated 5000 matrices composed of

150 random combinations of potential average demographic rates for the pupfish chosen from 
151 uniform distributions that sampled means between their possible minimum and maximum values

152 (Figure 2). This approach allowed exploration of the potential parameter space, resulting

153 distribution of reproductive value and elasticity for stage classes, and relationships among them.

154 A post-breeding projection was chosen to enable inclusion of eggs as a life stage because

155 they are potential targets for management. It was based on a life cycle diagram and projection

156 matrix with 3 stages (Figure 2): eggs, early life stage or ELS (from hatching at $4 \mathrm{~mm}$ to $11 \mathrm{~mm}$ in

157 length) and adults ( $>12 \mathrm{~mm})$. A 7-day time step was used based on the time required for an egg

158 to hatch and become an ELS. I converted DHP demographic rates expressed in the literature on a

159 monthly basis to a daily rate (divided by 30) and then to a weekly rate (multiplied by 7 ).

160 The model required estimates for the proportion of individuals that: (a) survive over a

161 time step and remain Adults $\left(P_{3}\right)$; (b) grow from Eggs and survive to become $E L S\left(G_{1}\right)$; and (c)

162 that grow from $E L S$ to become Adults $\left(G_{2}\right)$, or that survive and remain as $E L S\left(P_{2}\right)$. It also

163 required estimates for realized fecundity, which is the product of (d) the proportion of individuals

164 that survive and remain $\left(P_{3}\right.$ for $\left.A d u l t s\right)$ or that grow to a reproductive stage over the time step $\left(G_{2}\right.$

165 for $E L S$ ), and (e) their fecundity $\left(m_{3}\right)$. Because male fecundity was not known, rates were based

166 on females and sex ratio of eggs was assumed to be 50:50.

167 As the overall probability of survival $(S)$ for a stage class is $S=P+G$, I estimated the

168 proportion of individuals surviving and transitioning using the equation:

$$
G=\frac{S^{t}}{1+S+S^{2}+S^{3} \ldots S^{t-1}}
$$

172 where $t=$ number of time steps in a stage including the transition to the next stage. Estimating

$173 G_{2}$ in this manner reduced the number of demographic estimates the model required to four $\left(P_{3}\right.$,

$174 S_{2}, G_{1}$, and $\left.m_{3}\right)$, but required an estimate of the number of time steps a newly arrived ELS (4 mm)

175 needed to grow to be an adult $(>11 \mathrm{~mm})$. James $(\underline{1969, \text { p. 46 }})$ estimated growth rates of caged 
176 individuals of $4.7 \mathrm{~mm}$ per month for offspring in Devils Hole, which would require 1.6-2 months

177 (7-8 weeks) for growth from ELS to Adult. Hybrid DHP, which may grow faster than

178 nonhybrids, require 30-45 days to grow from hatching to adult (O. Feuerbacher, pers. comm.). I

179 let the number of weeks (time steps) that ELS require to reach adult size range from 4 to 7.

180 Monthly survival rates in the literature are based on best professional judgment, as a DHP

181 capture-recapture study has not been conducted in Devils Hole. Adult survival $\left(P_{3}\right)$ in Dzul et

182 al.'s ( $\underline{2013})$ model was assigned values of $0.70,0.80$, and 0.86 , while Chernoff $(\underline{1985})$ used 0.91.

183 I explored values ranging from 0.7 to 0.9 . Monthly survival $\left(S_{2}\right)$ assigned by Dzul et al. ( $\left.\underline{2013}\right)$ to

184 juveniles (ELS in my model) was $0.047,0.072$ and 0.097 , based primarily on simulation runs of

185 their model that resulted in the stable population growth observed during their one-year study. I

186 allowed ELS monthly survival to range between 0.05 and 0.15 .

187 Fecundity $\left(m_{3}\right)$ has not been measured for DHP in the wild. Females are thought to lay a

188 single egg with each spawn, which can occur at any time of year but peaks from mid-February to

189 mid-May with a secondary peak from July-Sept (ㅂausner et al. 2013; Lyons 2005). Fecundity is

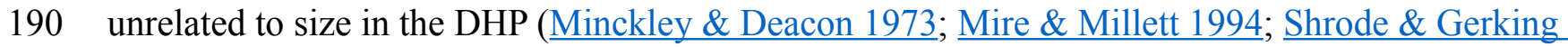

191 1977). Minckley and Deacon (1973) stated that "an average female may have about 4-5 ova or

$19210-20 \%$ of her total complement in a mature condition during a peak reproductive season." This

193 suggests that a female might be capable of laying 20-50 eggs during her lifetime (minimum 4 x 5

$194=20$; maximum: $5 \times 10=50$ ) and that the eggs would be distributed differentially during the

195 year. Chernoff (1985), using data in James (1969) and Minckley and Deacon (1973), estimated

196 the average number of eggs spawned per female to be 24 and the average per female per month

197 during the breeding season from 1-5. In summary, females may lay 0-4 eggs per week.

198 Assuming a 50:50 sex ratio, I set reproductive rates to range from as low as 0.05 female eggs per

199 week to as many as 2 female eggs per week. In the absence of hatching success measures, I 
assumed all eggs survived for one week and hatched, which may overemphasize their importance

201 to population dynamics.

\section{RESULTS}

\section{Estimation of Population Growth Measures}

204 Fits of density dependent and independent models of population growth (Table 1) reflect the shift

205 in pupfish dynamics over time (Figure 1). From 1972-1995, density dependent models provided 206 the best fit for both spring and fall counts (cumulative AIC weight of 0.99-1.0), with the logistic

207 model fitting best for both seasons (Table 1). Growth was positive before $1996(r=0.82 ; 95 \%$ CI

$208=0.40-1.24)$, with a carrying capacity of 216 (95\% CI: 194-237) for spring and 444 (95\% CI:

209 390-498) for fall. From 1996-2013, density independent models best fit the DHP counts, with a

210 declining population growth $(r)$ of $-0.049(95 \% \mathrm{CI}=-0.24-0.15)$ and $-0.088(95 \% \mathrm{CI}=-0.27-$

2110.09 ) for spring and fall counts, respectively. Associated values for annual environmental

212 variation were $\varepsilon=0.117$ for spring and $\varepsilon=0.096$ for fall.

\section{Count-based Risk Analysis for the DHP in Devils Hole}

214 Time to extinction for the DHP estimated separately from spring and fall counts followed the

215 expected logarithmic distribution, resulting in most simulated populations becoming extinct

216 within 50 years and a smaller number remaining extant for extended periods (Figure 3A).

217 Median and mean time to extinction were 26 and 27 years, and 17 and 22 years, respectively, for

218 spring and fall counts (Figure 3A). The chance of extinction within a decade was less than 5\%,

219 but rose rapidly to $26-33 \%$ by 20 years, $\sim 45 \%$ by 25 years, and $81-90 \%$ by 50 years (Figure 3B).

\section{Effect of Harvest for Captive Propagation on Extinction Risk in Devils Hole}


221 Risk to the wild population of removing pupfish from Devils Hole to initiate captive breeding

222 depended on the level and timing of harvest (Figure 4). Removing individuals in the fall had less

223 impact on risk to the wild population than the same level of harvest in spring, due to the larger

224 initial size of the pupfish population in fall. For both spring and fall harvest, risk increased

225 linearly with the number of individuals removed at rates of up to 6 pupfish per year for 3 years.

226 Above this level of harvest, extinction risk accelerated; the median time to extinction fell rapidly

227 (Figure 4A) and the probability of extinction increased at a greater rate (Figure 4C,D), especially 228 for spring harvest.

229 Surprisingly, extinction risk was relatively unaffected by the apportionment of the total

230 harvest among years (Figure 4B). Whether the total number of individuals was removed over

231 one, two or three years had little effect on the probability of extinction at year 20 years.

\section{Impact of Removing Different Age Classes on DHP Population Dynamics}

233 Analysis of reproductive value (RV) and elasticity both indicated that Adults were the stage class

234 with the greatest influence on population dynamics (Table 2). RV for ELS (Stage 2) was nearly

235 identical to RV of Eggs (Stage 1) and never exceeded 1.2 in the 5000 iterations of matrices

236 evaluated. RV for Adults, however, averaged $24.2 \pm 0.3$ and ranged from a minimum of 4.32 to a

237 maximum of 123 with a median value of 17.7 (Figure 5A). This pattern occurred partly because

238 so few ELS survived to become adults. Adult RV was strongly negatively related to ELS growth

239 and positively related to the stage duration (Figure 5B). Elasticity results also indicated that

240 changes in adult survival $\left(P_{3}\right)$ had by far the greatest influence on population growth rates (Table $2412)$.

242 Extinction Risk versus DHP Population Size in Devils Hole

243 As expected, the median time to extinction increased and probability of extinction in 10 years

244 decreased when simulations were begun with larger initial population sizes (Figure 6). Both 
245 metrics of extinction risk changed linearly with initial population sizes between 30 and 50

246 individuals, but accelerated when initial populations were less than 30 individuals.

\section{DISCUSSION}

248 The Devils Hole Pupfish has been threatened with extinction since the Endangered Species Act 249 was enacted. A count-based PVA suggests this population faces a $28-32 \%$ chance of going 250 extinct in the wild over the next 20 years (Figure 3), but could disappear within 7 years. This 251 analysis undoubtedly underestimates extinction risk, as my model does not explicitly incorporate 252 the effects of inbreeding, demographic stochasticity, and catastrophes (Mangel \& Tier 1994; Ralls 253 et al. 2002), depending instead on their intrinsic influences being accounted for in the estimates 254 of population growth and its variances derived from pupfish counts. Nevertheless, the projected 255 risk of extinction is moderately high; for comparison, IUCN red list criteria based on extinction 256 risk from a PVA associates "Critically Endangered" with forecasts of 50\% extinction within 10 257 years and "Endangered" with forecasts of 20\% extinction within 20 years (IUCN 2014). Even

258 when the population was growing or stable from 1972-1995, the average long-term carrying 259 capacity in Devils Hole was small (216 in spring and 444 in fall), as estimated from logistic

260 population growth (Table 1). Thus, despite the lack of long-term success with captive

261 propagation and refuge populations in the past, the need to establish a secure population outside

262 Devils Hole is greater than ever if this species is to persist.

\section{Risks to the Wild Population when Building the Captive Population}

Removing individuals from the wild to initiate captive breeding will reduce the time to extinction of pupfish in Devils Hole (Figure 4). Risks can be mitigated by harvesting wild pupfish in the fall, when the population tends to be larger, rather than in the spring, when less

267 recruitment has occurred. However, risk to the wild population accelerated when more than six 268 adults were harvested annually, although this effect is smaller in the fall. In any case, it may be 
unwise to harvest adults for captive propagation if eggs or early life-stage individuals are available and can be raised in captivity. Removing eggs has the least impact on the population

271 dynamics of DHP in Devils Hole (Figure 5, Table 2). The egg stage had the lowest reproductive

272 value and the lowest elasticity, although population dynamics was nearly as insensitive to

273 incremental, instantaneous changes in the rates of early life stage individuals.

274 Results from the two population models can be connected by translating reproductive

275 value of the egg stage from the demographic matrix model to a number of adults that can be

276 removed in the count-based models. The mean $\mathrm{RV}$ of an adult pupfish is roughly 25 times

277 greater than that of a pupfish egg in Devils Hole (Table 2). From this perspective, removing 25

278 eggs for captive breeding is equivalent to removing a single adult in terms of its influence on 279 population dynamics (Caswell 2001).

280 The success of removing pupfish eggs or adults to build the captive population and 281 support the wild population depends upon subsequent husbandry and (re)introduction. This

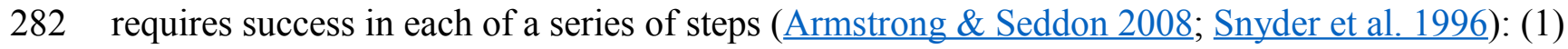
283 survival, growth and reproduction in captivity; (2) maintenance in captivity of genetic diversity 284 and a viable gene pool; and (3) successful preconditioning and release to the wild, either to 285 establish a new refuge in a secure location or to bolster the pupfish in Devils Hole, ideally after 286 conditions that caused the population to decline have been identified and ameliorated. While the

287 first step in the process has been successfully accomplished, as eggs taken from Devils Hole have 288 been hatched in captivity, serious obstacles remain before releases of pupfish can occur.

289 Unfortunately, the longer that pupfish remain in captivity before being returned to the wild, the 290 greater the likelihood of selection for domestication and loss of behaviors needed to survive in 291 the wild (Ford et al. 2008; Frankham 2008; Kelley et al. 2006; Snyder et al. 1996). Avoidance of

292 domestication will be a key priority in managing the captive population (Lee H. Simons, pers. 293 comm., 3 June 2014). 


\section{When to Designate the "Condor Moment" and Remove All Pupfish from Devils Hole}

295 Designating the "California Condor moment" for the DHP - when removing the

296 remaining pupfish from Devils Hole would be the best course of action - is a management option

297 conservation biologists have rarely considered. Similar situations have been faced in a few other

298 extreme cases, such as the Hawaiian Crow (Corvus hawaiiensis) which was rescued from

299 extinction but cannot be reintroduced to the wild due to the persistence of the toxoplasmosis

300 responsible for its decline (Work et al. 2000), and the black-footed ferret (Mustela nigripes)

301 which was captured for captive breeding after a few individuals were rediscovered in the 1980's

302 (Clark 1990; Jachowski et al. 2011). I evaluated when to designate the condor moment by

303 searching for nonlinearity in the relationship between risk of extinction and population size

304 (Figure 6). Extinction risk accelerated when population size fell below 30 individuals. However,

305 the risk analysis presented here only partly addresses the issue of when to intervene by removing

306 all individuals from the wild to save the DHP. The degree that genetic diversity of the wild

307 population is represented in the captive population is a major concern that the model does not

308 address.

309 There are many similarities between the situation currently facing the DHP and the

310 decline of the California Condor in the mid-1980s (Meretsky et al. 2000; Snyder \& Snyder 2000;

311 Snyder \& Snyder 1989). Both species experienced a rapid population decline occurring over

312 decades as a result of poorly understood causes that were difficult to reverse. Neither species had

313 a history of successful captive breeding, although experiences with the target or a surrogate

314 species indicated the potential for success. Neither species was sufficiently represented in

315 captivity to conserve genetic diversity. Concerns were voiced for condors that capturing the

316 remaining individuals for captive breeding would reduce the need to conserve of habitats needed

317 for their reintroduction, and similar issues relating to water rights affect the pupfish. Finally, a 
318 long history of management controversies and struggles to conserve each species has made them

319 conservation icons.

320 Some key differences, however, between pupfish and condor life history and management

321 could make it easier to recover the DHP. First, the "faster" life history of the DHP (early

322 maturation, reproduction and short life span) promotes rapid population growth and recovery

323 compared to the "slower" life history" of the condor (delayed age of first breeding, low level of

324 reproduction and long life span). Yet, it also dictates that immediate reproductive success in

325 captivity must occur, given the one year lifespan of the pupfish. Second, reintroduction of

326 captive-reared DHP to the wild should be much easier than it has been for the condor.

327 Reintroduction of condors has been on-going for two decades without achieving a self-supporting

328 population due to poisoning from ingestion of lead fragments in their food, excessive tameness of

329 released birds, parents feeding microtrash to nestlings, and other causes of mortality (Meretsky et

330 al. 2000; Walters et al. 2010). DHP habitat is protected and threats to the species should be easier

331 to control, at least in theory.

332 As a result of the potential for fast population growth in captivity, it is not be too late to

333 rescue the Devils Hole pupfish from extinction. Needed now to ensure success is a diagnosis of

334 the causes of decline in Devils Hole in order to recover the wild population, an evaluation of the

335 extent that the DHP harbors a significant genetic load and whether this requires a genetic

336 restoration strategy (Martin et al. 2012), an analysis of the risks (e.g., introduction of diseases or

337 parasites) and benefits (e.g., genetic and demographic rescue) of connectivity between the captive

338 population and Devils Hole, and an evaluation of locations for new refugia to introduce the

339 pupfish and better analysis of why refugia failed in the past. Of key importance will be

340 maintaining the wild pupfish population in Devils Hole, while launching the new captive

341 breeding facility. 
342

343 This manuscript benefitted greatly from input of the participants at the Devils Hole Pupfish Risk

344 Analysis Workshop (8 Nov. 2013), and from reviews by Christopher Clements, Daniel Gaines,

345 Sean Maher, J. Michael Reed, Lee Simons, Noel F. R. Snyder, Ian Watson, Kevin Wilson, and the

346 Beissinger lab.

347

348

349

350

351

352

353

354

355

356

357

358

359

360

361

362

363

364

\section{REFERENCES}

Andersen ME, and Deacon JE. 2001. Population size of Devils Hole pupfish (Cyprinodon diabolis) correlates with water level. Copeia 2001:224-228.

Armstrong DP, and Seddon PJ. 2008. Directions in reintroduction biology. Trends in Ecology \& Evolution 23:20-25.

Baugh TM, and Deacon JE. 1983a. Daily and yearly movement of the Devils Hole pupfish Cyprinodon diabolis in Devils Hole, Nevada. Great Basin Naturalist 43:592-596.

Baugh TM, and Deacon JE. 1983b. Maintaining the Devils Hole pupfish, Cyprinodon diabolis Wales, in aquaria. Journal of Aquaculture and Aquatic Science 3:73-75.

Baugh TM, and Deacon JE. 1988. Evaluation of the role of refugia in conservation efforts for the Devils Hole pupfish, Cyprinodon diabolis wales. Zoo Biology 7:351-358.

Beissinger SR, and McCullough DR. 2002. Population Viability Analysis. Chicago, Illinois: University of Chicago Press.

Burnham KP, and Anderson DR. 2002. Model selection and inference: a practical theoretic approach. New York: Springer-Verlag.

Caswell H. 2001. Matrix Population Models. Sunderland, Massachusetts: Sinauer and Associates. Chernoff B. 1985. Population dynamics of the Devils Hole pupfish. Environmental Biology of Fishes 13:139-147. 
365 Clark TW. 1990. Black-footed ferrets on the road to recovery. Endangered Species Update 8:86$366 \quad 88$.

367 Deacon JE, Taylor FR, and Pedretti JW. 1995. Egg viability and ecology of Devils Hole pupfish:

368 insights from captive propagation. Southwestern Naturalist 40:216-223.

369 Dzul MC, Dinsmore SJ, Quist MC, Gaines DB, Wilson KP, Bower MR, and Dixon PM. 2013. A

370 simulation model of the Devils Hole pupfish population using monthly length-frequency

$371 \quad$ distributions. Population Ecology 55:325-341.

372 Dzul MC, Quist MC, Dinsmore SJ, Dixon PM, Bower MR, Wilson KP, and Gaines DB. 2012.

373 Identifying sources of error in surveys of Devils Hole pupfish (Cyprinodon diabolis)

$374 \quad$ Southwestern Naturalist 57:44-50.

375 Ford MJ, Hard JJ, Boelts B, LaHood E, and Miller J. 2008. Estimates of natural selection in a

376 salmon population in captive and natural Environments. Conservation Biology 22:783-

$377 \quad 794$.

378 Frankham R. 2008. Genetic adaptation to captivity in species conservation programs. Molecular $379 \quad$ Ecology 17:325-333.

380 Hausner MB, Wilson KP, Gaines DB, Suarez F, and Tyler SW. 2013. The shallow thermal regime

381 of Devils Hole, Death Valley National Park. Limnology \& Oceanography: Fluids \&

$382 \quad$ Environments 3:119-138.

383 Hillyard S, Burg G, McKenna K, Urbina N, and van Breukelen F. 2014. Oxygen consumption in 384 a hot hypoxic world, the Devils Hole pupfish (879.24). The FASEB Journal 28.

385 IUCN. 2014. IUCN Red List of Threatened Species: 1994 Categories \& Criteria. . Available at 386 http://www.iucnredlist.org/static/categories_criteria_2_3\#categories (accessed July 387 2014). 
388 Jachowski DS, Gitzen RA, Grenier MB, Holmes B, and Millspaugh JJ. 2011. The importance of thinking big: Large-scale prey conservation drives black-footed ferret reintroduction success. Biological Conservation 144:1560-1566.

391 James CJ. 1969. Aspects of the ecology of the Devils Hole pupfish, (Cyprinodon diabolis) Wales.

392 M.S. University of Nevada.

393 Karam AP. 2005. History and development of refuge management for Devils Hole pupfish (Cyprinodon diabolis) and an ecological comparison of three artificial refuges Masters thesis. Southern Oregon University.

Kelley JL, Magurran AE, and Macías García C. 2006. Captive breeding promotes aggression in an endangered Mexican fish. Biological Conservation 133:169-177.

Lele SR, Moreno M, and Bayne E. 2012. Dealing with detection error in site occupancy surveys: what can we do with a single survey? Journal of Plant Ecology 5:22-31.

Lema SC, and Nevitt GA. 2006. Testing an ecophysiological mechanism of morphological plasticity in pupfish and its relevance to conservation efforts for endangered Devils Hole pupfish. Journal of Experimental Biology 209:3499-3509.

Lotts KC, Waite TA, and Vucetich JA. 2004. Reliability of absolute and relative predictions of population persistence based on time series. Conservation Biology 18:1224-1232.

Lyons LT. 2005. Temporal and spatial variation in larval Devils Hole pupfish (Cyprinodon diabolis) abundance and associated microhabitat variables in Devils Hole, Nevada.

408 Mangel M, and Tier C. 1994. Four facts every conservation biologist should know about $409 \quad$ persistence. Ecology 75:607-614.

410 Manning L, and Wullschleger J. 2004. Devils Hole update. Proceedings of the Desert Fishes Council 36:38. 
412 Martin AP, Echelle AA, Zegers G, Baker S, and Keeler-Foster CL. 2012. Dramatic shifts in the

413

414

415 McCarthy MA, Andelman SJ, and Possingham HP. 2003. Reliability of relative predictions in $416 \quad$ population viability analysis. Conservation Biology 17:982-989.

417 Meretsky VJ, Snyder NFR, Beissinger SR, Clendenen DA, and Wiley JW. 2000. Demography of 418 gene pool of a managed population of an endangered species may be exacerbated by high genetic load. Conservation Genetics 13:349-358. the California Condor: implications for reestablishment. Conservation Biology 14:957967.

Minckley CO, and Deacon JE. 1973. Observations on the reproductive cycle of Cyprinodon diabolis. Copeia 1973:610-613.

Mire JB, and Millett L. 1994. Size of mother does not determine size of eggs or fry in the Owens pupfish, Cyprinodon radiosus. Copeia 1994:100-107.

Morris WF, and Doak DF. 2002. Quantitative Conservation Biology: Theory and Practice of Population Viability Analysis. Sunderland, MA: Sinauer Associates.

Ralls K, Beissinger SR, and Cochrane JF. 2002. Guidelines for using PVA in endangered species management. In: Beissinger SR, and McCullough DR, eds. Population Viability Analysis. Chicago, Illinois: University of Chicago Press, 521-550.

Reed JM, Mills LS, Dunning JB, Menges ES, McKelvey KS, Frye R, Beissinger SR, Anstett MC, and Miller P. 2002. Emerging issues in population viability analysis. Conservation Biology 16:7-19.

Riggs AC, and Deacon JE. 2004. Connectivity in Desert Aquatic Ecosystems: The Devils Hole Story. In: Sada DW, and Sharpe SE, editors. Spring-fed Wetlands: Important Scientific and Cultural Resources of the Intermountain Region. Las Vegas, Nevada: Desert Research Institute. p 38. 
Royle JA, and Dorazio RM. 2008. Hierarchical Modeling and Inference in Ecology. San Diego, CA: Academic Press.

Shrode JD, and Gerking SD. 1977. Effects of constant and fluctuation temperatures on reproductive performance of a desert pupfish, Cyprinodon n. nevadensis. Physiological Zoology 50:1-10.

Snyder NFR, Derrickson SR, Beissinger SR, Wiley JW, Smith TB, Toone WD, and Miller B. 1996. Limitations of captive breeding in endangered species recovery. Conservation Biology 10:338-348.

Snyder NFR, and Snyder H. 2000. The California Condor: a saga of natural history and conservation: Princeton University Press.

Snyder NFR, and Snyder HA. 1989. Biology and conservation of the California Condor. Current Ornithology 6:175-267.

Solymos P, Lele S, and Bayne E. 2012. Conditional likelihood approach for analyzing single visit abundance survey data in the presence of zero inflation and detection error. Environmetrics 23:197-205.

Szabo BJ, Kolesar PT, Riggs AC, Winograd IJ, and Ludwig KR. 1994. Paleoclimatic inferences from a 120,000-yr calcite record of water-table fluctuation in browns room of DevilsHole, Nevada. Quaternary Research 41:59-69.

U.S.N.P.S. 2012. History of Devils Hole pupfish refuges. Unpublished report. Death Valley National Park. p 11.

Walters JR, Derrickson SR, Fry DM, Haig SM, Marzluff JM, and Wunderle JM, Jr. 2010. Status of the California Condor (Gymnogyps californianus) and efforts to achieve its recovery. Auk 127:969-1001. 
459 Wilcox JL, and Martin AP. 2006. The devil's in the details: genetic and phenotypic divergence

460 between artificial and native populations of the endangered pupfish (Cyprinodon

461 diabolis). Animal Conservation 9:316-321.

462 Work TM, Massey JG, Rideout BA, Gardiner CH, Ledig DB, Kwok OCH, and Dubey JP. 2000.

463 Fatal toxoplasmosis in free-ranging endangered 'Alala from Hawaii. Journal of Wildlife

464 Diseases 36:205-212. 
466 Figure 1. Maximum spring and fall counts of the Devils Hole pupfish.

467 Figure 2. Devils Hole pupfish postbreeding life cycle, projection matrix, and range of weekly 468 demographic rates used in creating matrices for analysis.

469 Figure 3. Risk projections for Devils Hole pupfish based on estimates from Spring and Fall 470 counts (A) time to extinction; and (B) probability of extinction.

471 Figure 4. Pupfish extinction risk in Devils Hole as in relation to (A) harvest season (spring or

472 fall), (B) apportionment of the total number of individuals harvested among 1, 2 or 3 years; and 473 harvest level (0-14 fish per year for 3 years)

474 Figure 5. A. Distribution of the Reproductive Value (RV) for Adults (stage 3) scaled relative to 475 Eggs (stage 1). B. Scatterplots of Adult RV (scaled) versus demographic rates used a input for 476 the matrix model, color coded by ELS stage duration or the number of weeks required to reach 477 adult size $(4=$ blue, $5=$ purple, $6=$ black and $7=$ green $)$.

478 Figure 6. Extinction risk (circles $=$ median time to extinction; squares $=$ probability of extinction 479 in 10 years) versus population size at the start of the simulation for spring (blue) and fall (red). 


\section{Figure 1}

Maximum spring and fall counts of the Devils Hole pupfish.

Figure 1 . Maximum spring and fall counts of the Devils Hole pupfish.

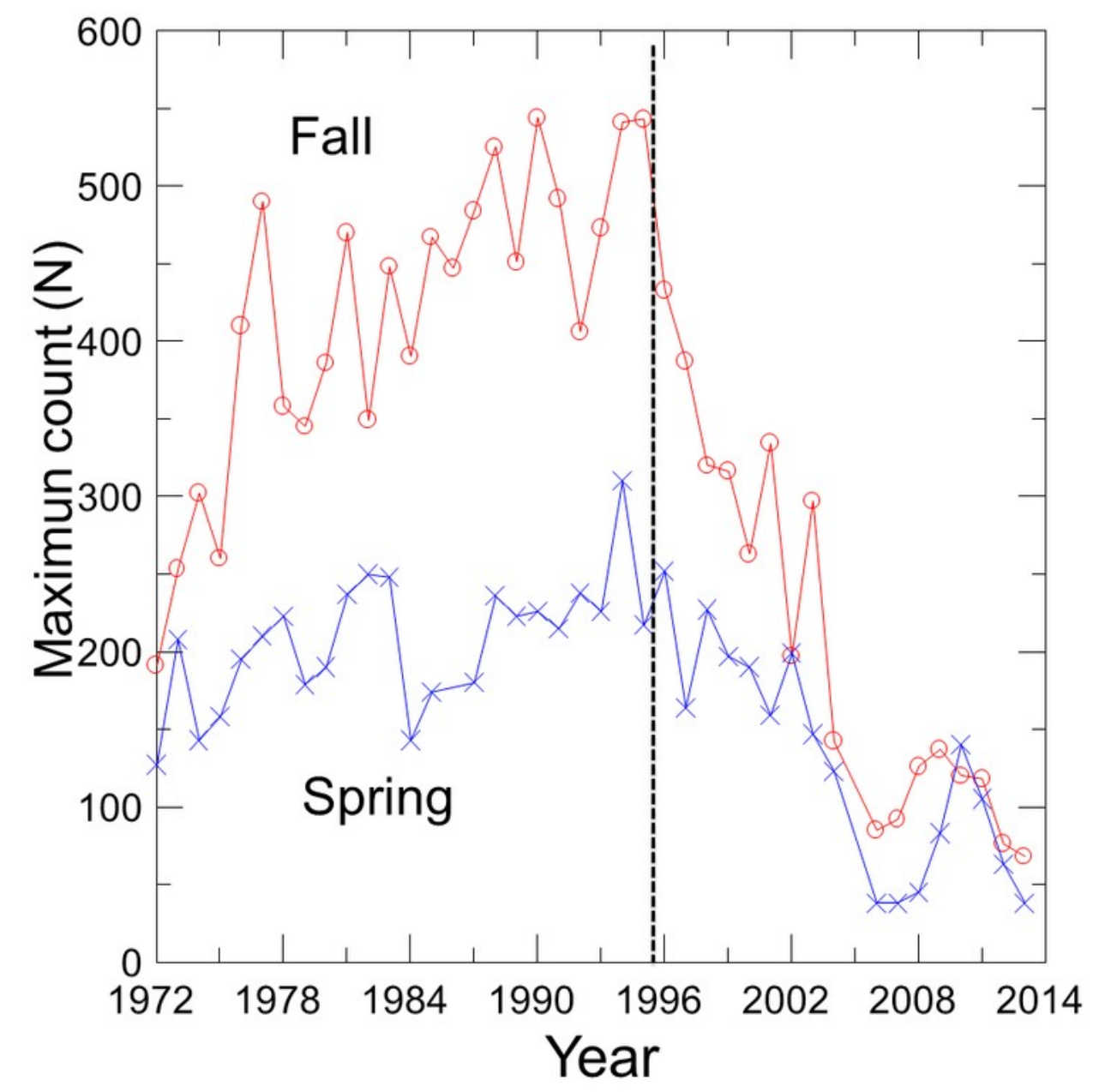




\section{Figure 2}

Devils Hole pupfish postbreeding life cycle, projection matrix, and

Figure 2. Devils Hole pupfish postbreeding life cycle, projection matrix, and range of weekly demographic rates used in creating matrices for analysis.

$$
\text { denographic rates used hin ciealing matices lor analysis. }
$$

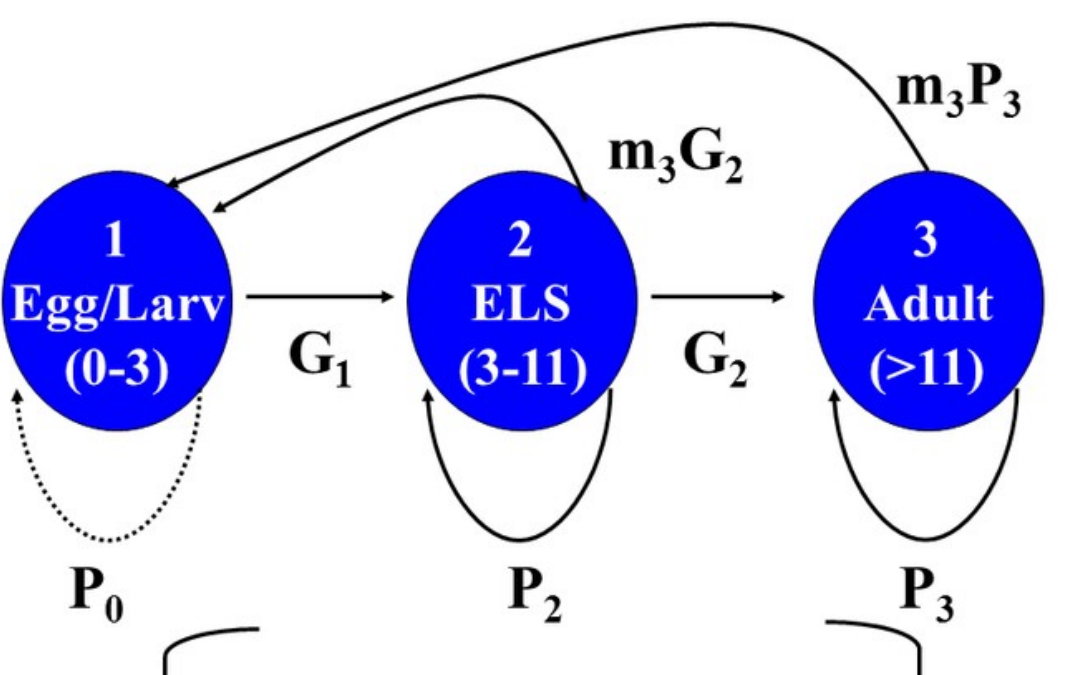

$\underline{\text { Rate }}$

Fecundity $(m)$

Survival $(P)$

Growth $(G)$
$\underline{\operatorname{Egg}(1)}$

$$
\mathrm{x}
$$

$\mathrm{x}$

1 $\mathrm{m}_{3} \mathrm{G}_{2} \quad \mathrm{~m}_{3} \mathrm{P}_{3}$

$\mathrm{P}_{2}$

$\mathrm{G}_{2}$
0

$\mathrm{P}_{3}$

Projection Matrix

$\underline{\operatorname{ELS}(2)}$

$\mathrm{x}$

$0.481-0.595$

$0.016-0.047$ $\underline{\text { Adult (3) }}$

$0.05-2.00$

0.920-0.977

$\mathrm{X}$ 


\section{Figure 3}

Risk projections for Devils Hole pupfish

Figure 3. Risk projections for Devils Hole pupfish based on estimates from Spring and Fall counts (A) time to extinction; and (B) probability of extinction. 


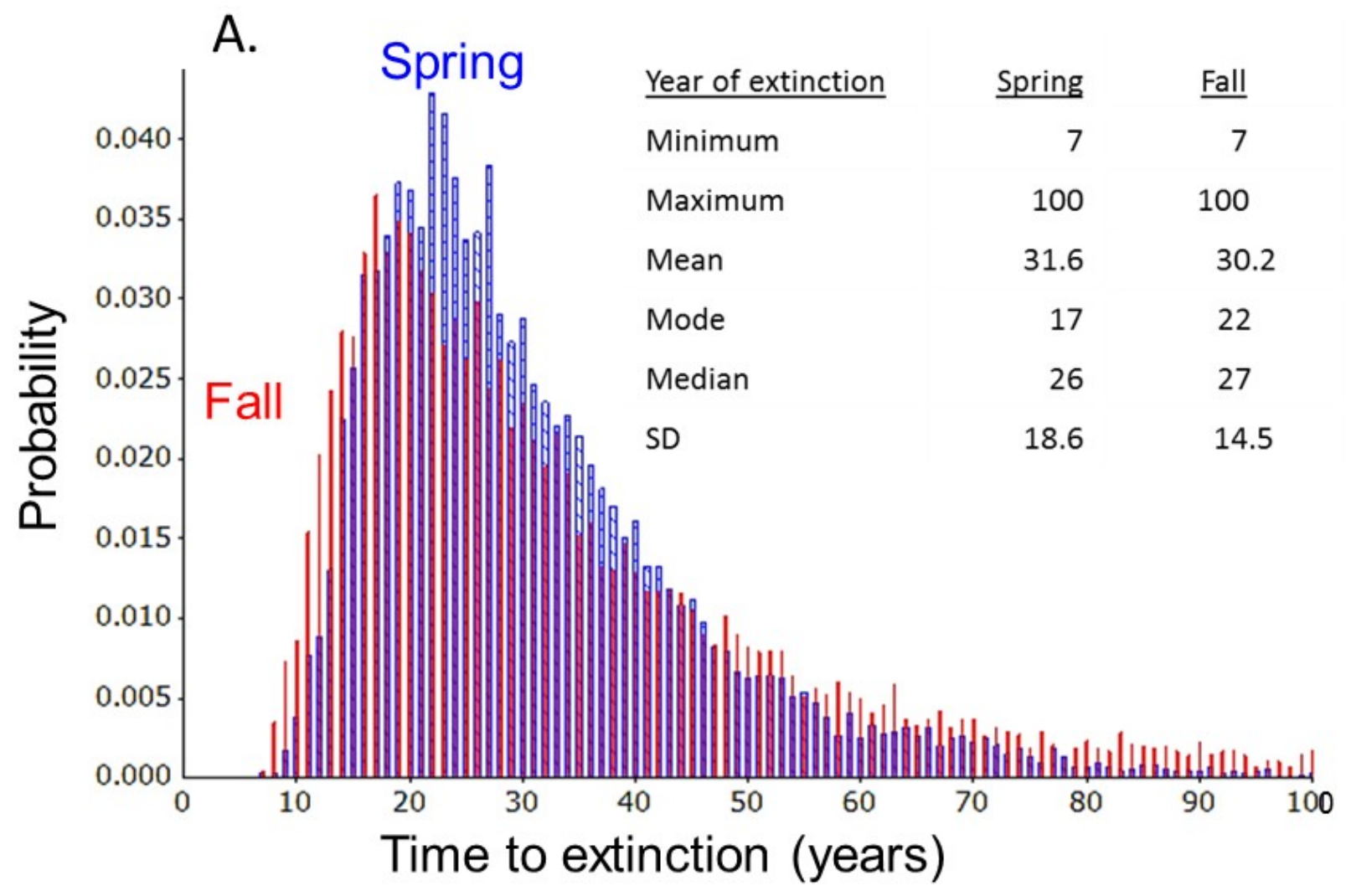

B.

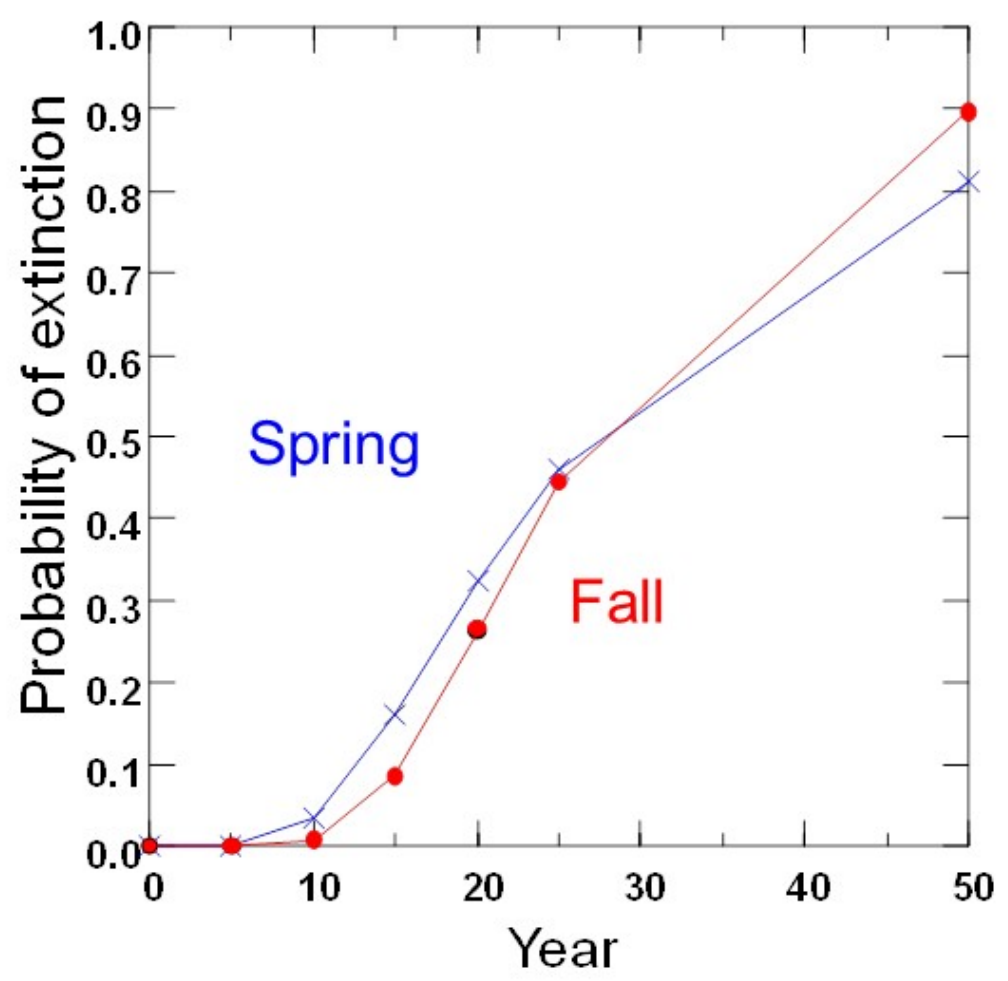




\section{Figure 4}

Pupfish extinction risk in Devils Hole in relation to:

Figure 4. Pupfish extinction risk in Devils Hole in relation to (A) harvest season (spring or fall), (B) apportionment of the total number of individuals harvested among 1, 2 or 3 years; and harvest level (0-14 fish per year for 3 years).

A.

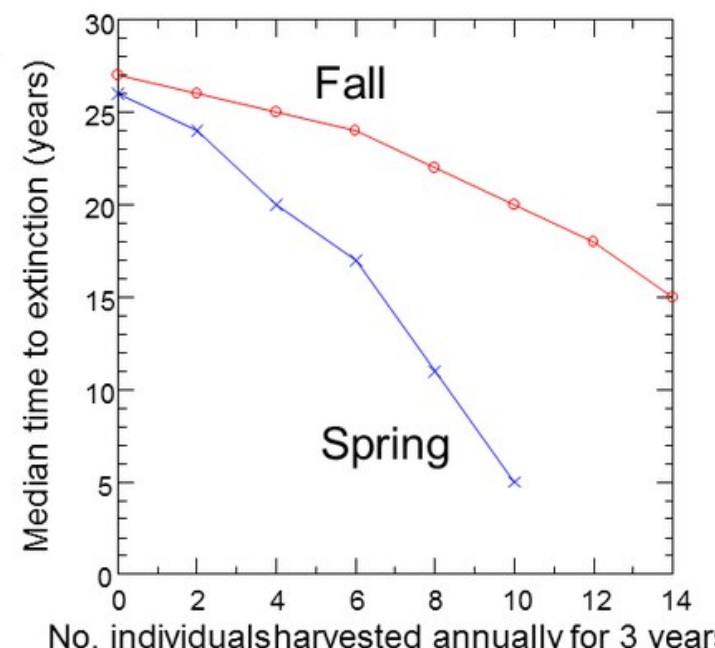

C.

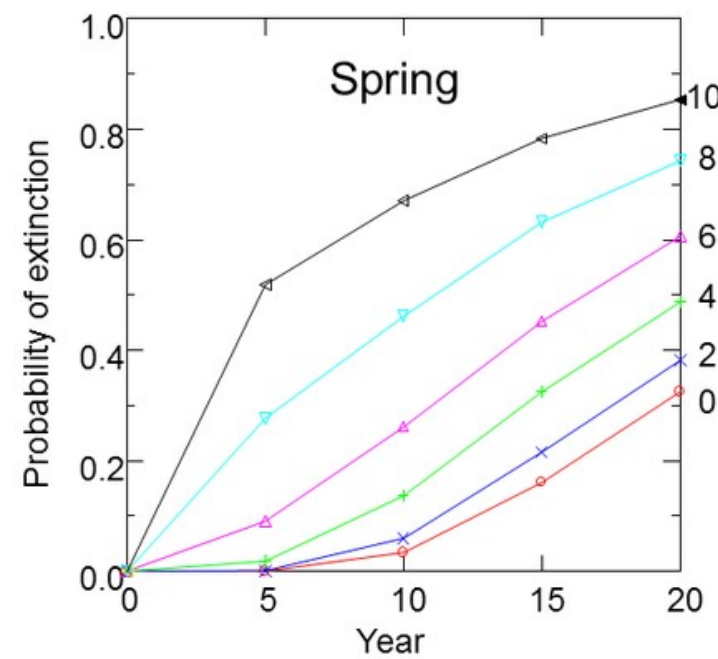

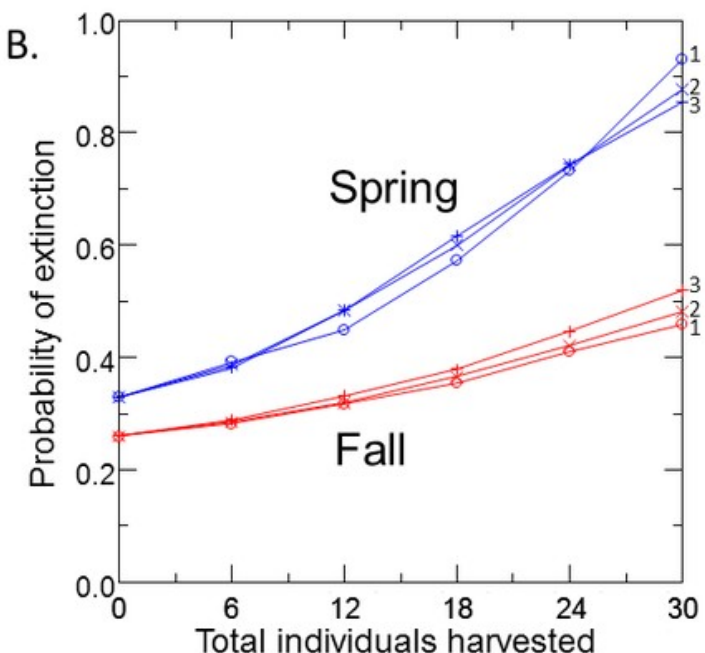

D.

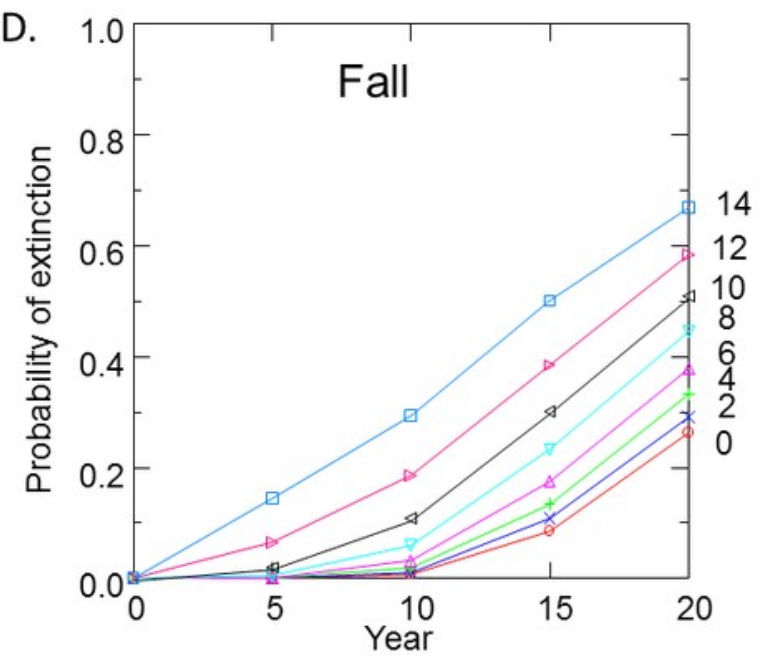




\section{Figure 5}

\section{Reproductive Value (RV)}

Figure 5. A. Distribution of the Reproductive Value (RV) for Adults (stage 3) scaled relative to Eggs (stage 1). B. Scatterplots of Adult RV (scaled) versus demographic rates used a input for the matrix model, color coded by ELS stage duration or the number of weeks required to reach adult size $(4=$ blue, $5=$ purple, $6=$ black and $7=$ green $)$. 


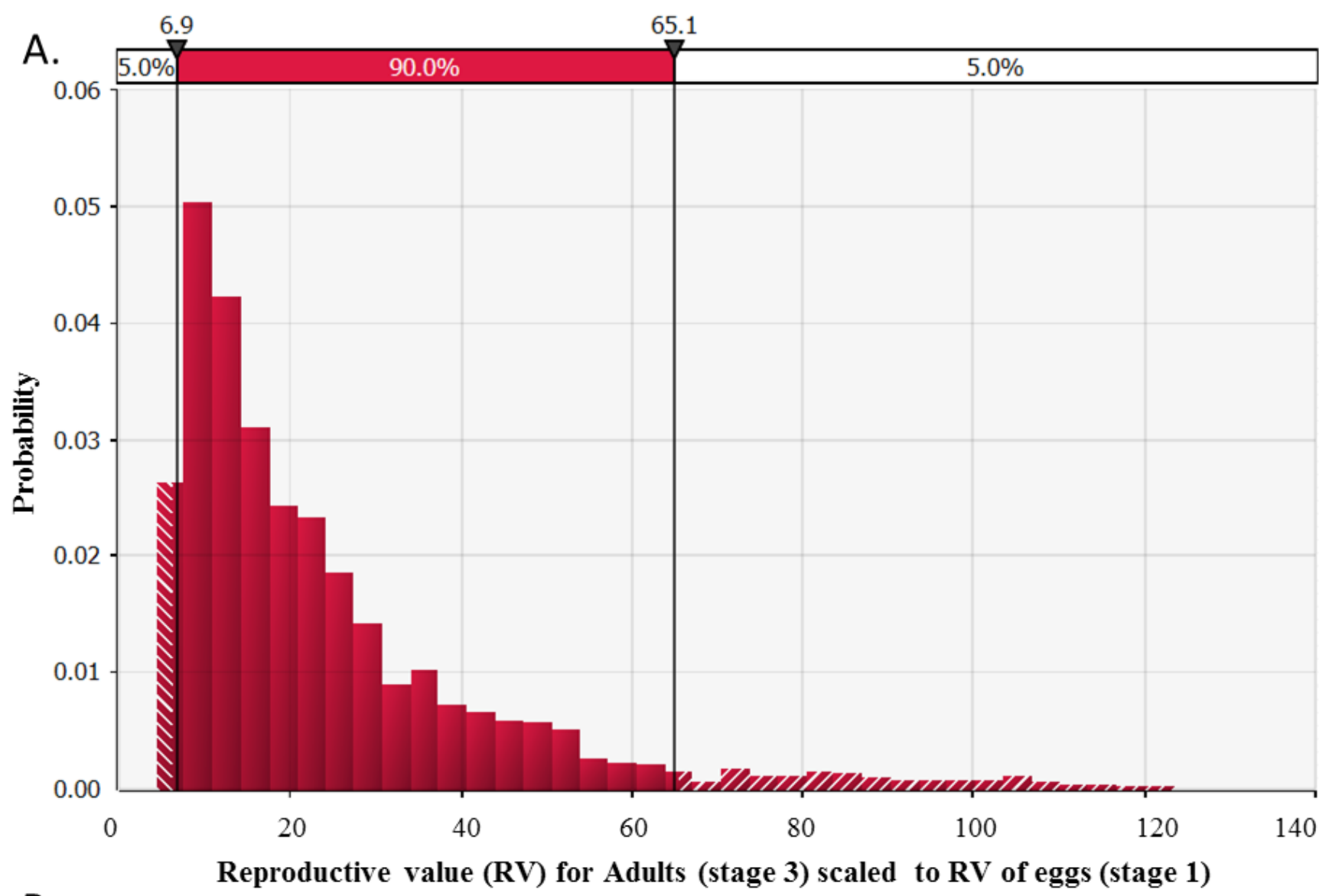

B.
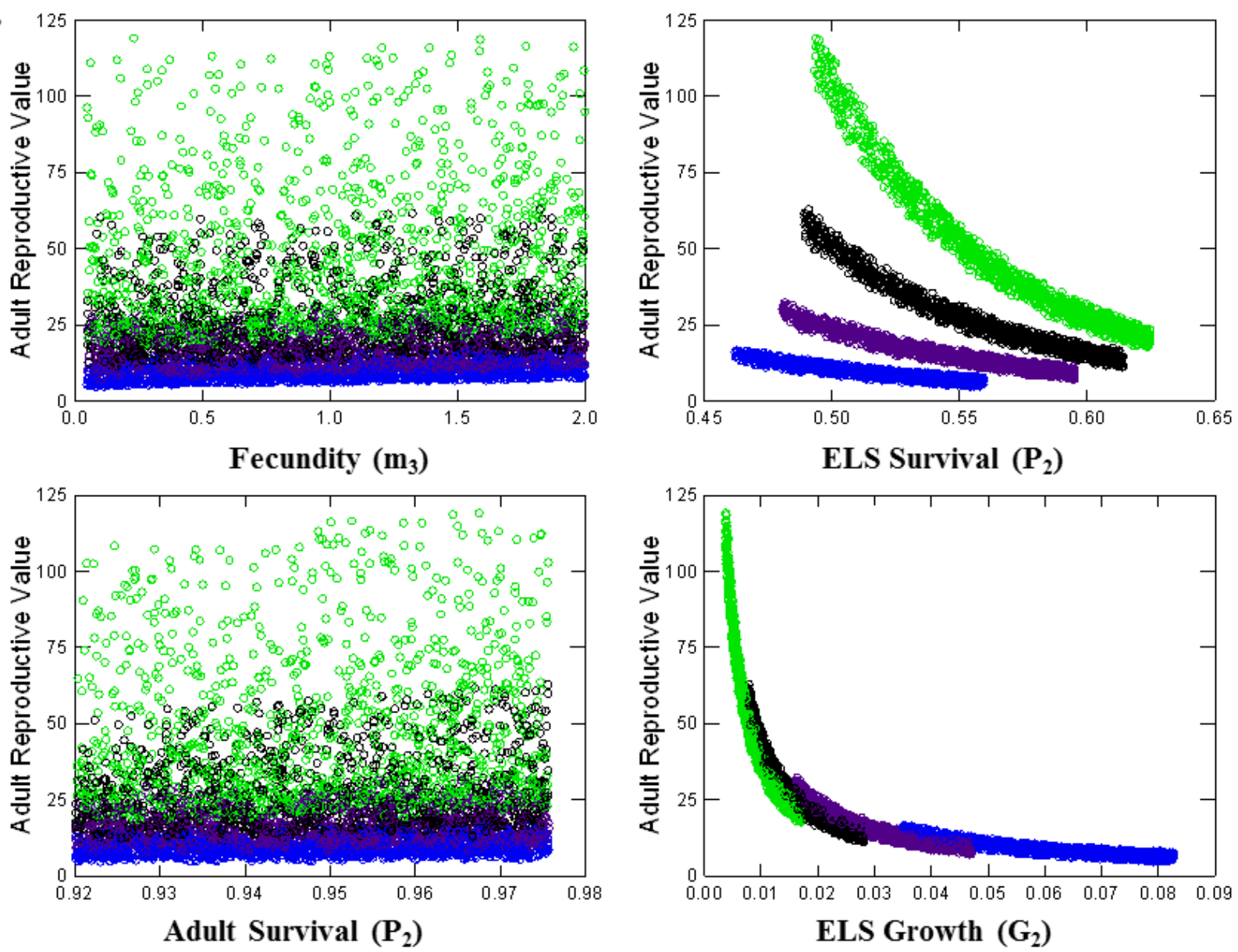


\section{Figure 6}

Extinction risk vs. population size

(circles $=$ median time to extinction; squares $=$ probability of extinction in 10 years) versus population size at the start of the simulation for spring (blue) and fall (red).

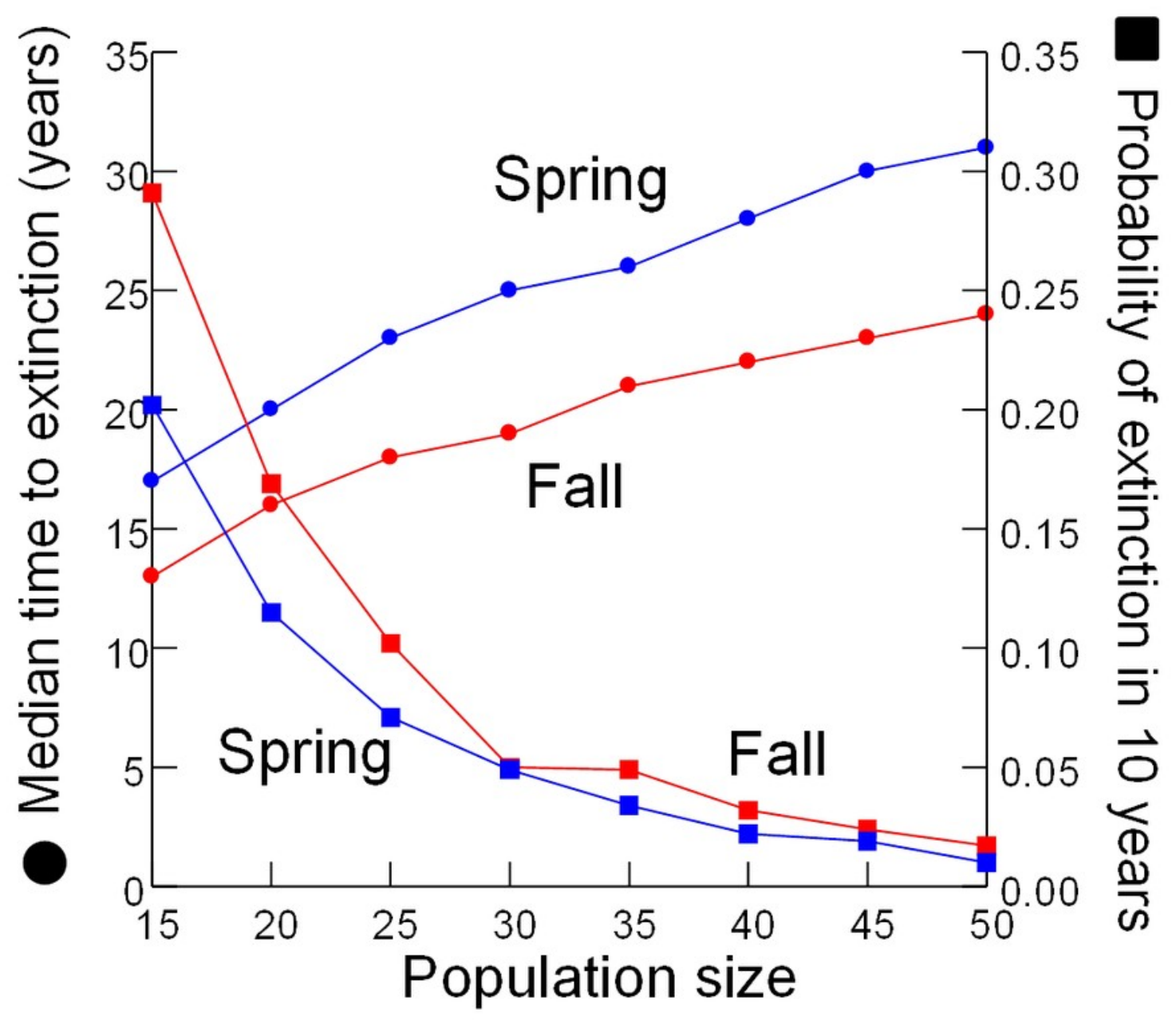




\section{Table 1 (on next page)}

Model selection and model estimates for DHP counts by time period.

Model selection and model estimates for DHP counts by time period. Bolded models are the best, based on their AICc score for the years and seasons evaluated. AICc weight (wt) indicates the strength of a model relative to other models in that set of years and season. 
Table 1. Model selection and model estimates for DHP counts by time period. Bolded models are the best, based on their AICc score for the years and seasons evaluated. AICc weight (wt) indicates the strength of a model relative to other models in that set of years and season.

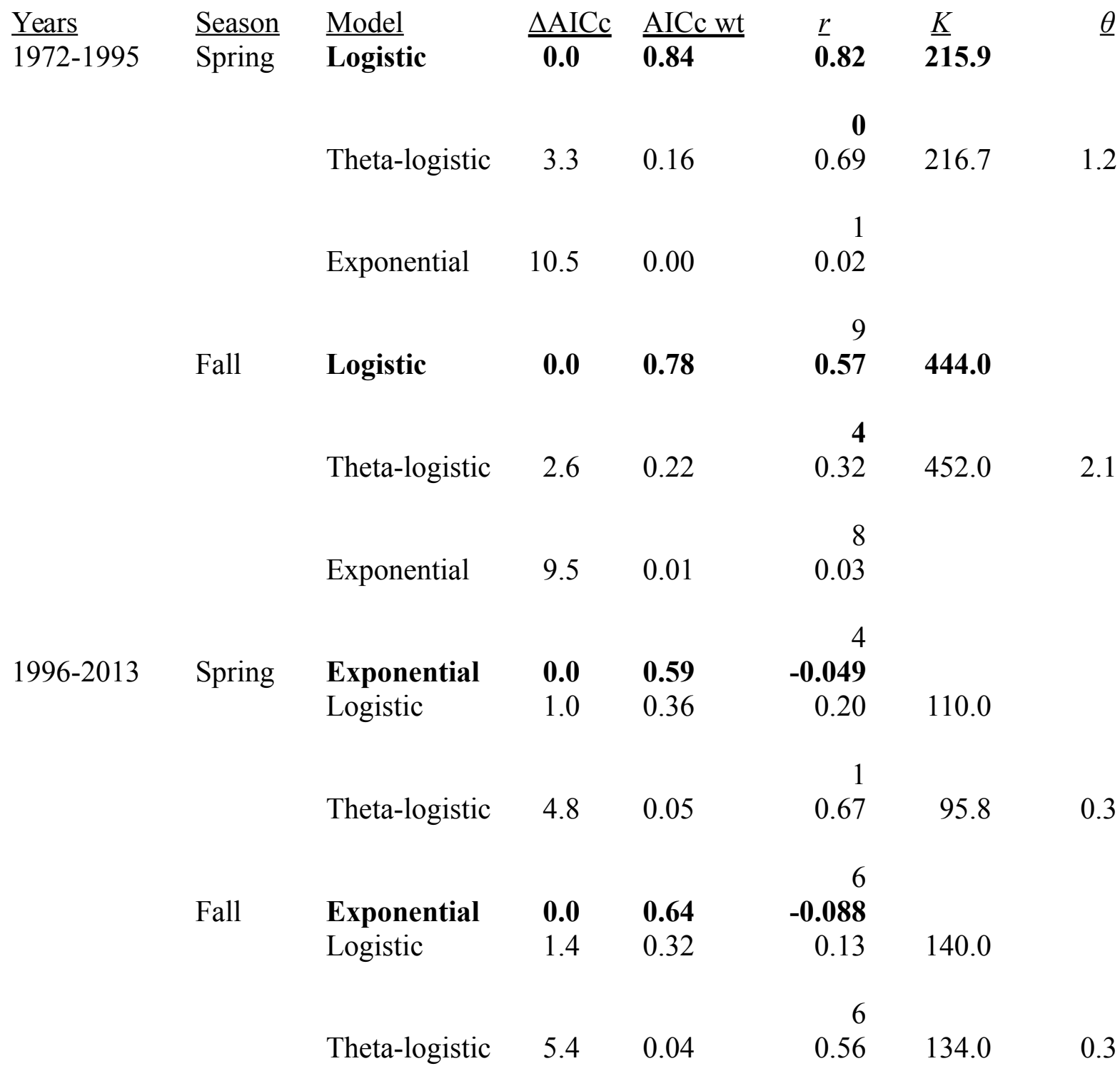




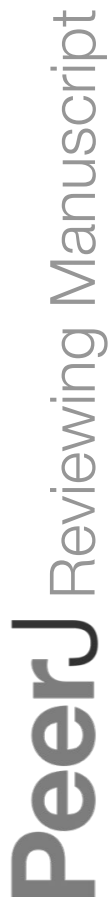

PeerJ reviewing PDF | (v2014:06:2265:1:0:ACCEPTED 7 Aug 2014) 


\section{Table 2 (on next page)}

Reproductive values ( + 1 SE) scaled relative to Eggs (stage 1) and elasticity from analyses of 5000 potential demographic matrices of the Devils Hole pupfish.

See Figure 2 for life cycle diagram, matrix construction and rates. 
Table 2. Reproductive values $( \pm 1 \mathrm{SE})$ scaled relative to Eggs (stage 1$)$ and elasticity from analyses of 5000 potential demographic matrices of the Devils Hole pupfish. See Figure 2 for life cycle diagram, matrix construction and rates.

Elasticity

\begin{tabular}{lcccc}
\hline & & & & \\
& Reproductive value & Fecundity & Growth & Survival \\
Life Stage & $(\mathrm{RV})$ & $(G m$ or $P m)$ & $(G)$ & $(P)$ \\
\cline { 2 - 5 } Egg (1) & 1.00 & 0 & 0.049 & 0 \\
ELS (2) & $1.01 \pm 0.01$ & 0.004 & 0.056 & 0.045 \\
Adult (3) & $\mathbf{2 4 . 4 \pm \mathbf { 0 . 2 9 }}$ & 0.045 & 0 & $\mathbf{0 . 8 0 0}$
\end{tabular}

